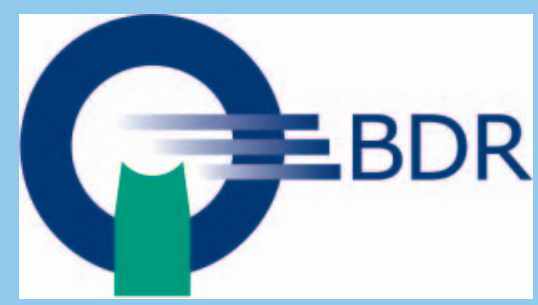

\title{
Radiologie Update 2021 - Ausblick 2022
}

Sehr geehrte Kolleginnen und Kollegen, nachdem wir 2020 das Radiologie Update bedingt durch die Corona-Pandemie ausfallen lassen mussten, war es eine besondere Freude, dass wir im März 2021 das Update wieder durchführen konnten. Wie bei so vielen Veranstaltern forderte dies auch uns einige Improvisationsfähigkeit und Flexibilität ab, insbesondere auch den Referentinnen und Referenten der Veranstaltungen. Bei anhaltender Pandemielage führten wir die Veranstaltung im Hybridformat durch und konnten den fast 250 zählenden Teilnehmerinnen und Teilnehmern ein interessantes und technisch perfekt vorbereitetes Programm bieten. Die beiden Kongresstage fassten wiederum die aktuellen Erneuerungen mit hoher praktischer und klinischer Relevanz zusammen - von der Neuroradiologie über die allgemeine Radiologie bis hin zur Kinderradiologie.

Als neue Referentinnen und Referenten konnten wir Prof. Ringe von der Medizinischen Hochschule Hannover für den Bereich Leber gewinnen sowie Prof. Henkes vom Klinikum Stuttgart für den Bereich Interventionelle Neuroradiologie. Bezüglich Arzthaftung und darüber hinaus fasste Frau Rechtsanwältin Dr. Gaibler die aktuelle Rechtslage zusammen. Rechtsanwalt Markus Henkel vom Berufsverband der Deutschen Radiologen referierte zum Thema „Fachfremde MRT-/CT-Leistungen“ und den hierfür relevanten gesetzlichen und rechtlichen Rahmenbedingungen wie der neuen Weiterbildungsordnung und beispielsweise dem Heilberufe-Kammergesetz in Bayern. Prof. Forsting aus Essen hielt in gewohnt erfrischender Weise die KeynoteLecture.

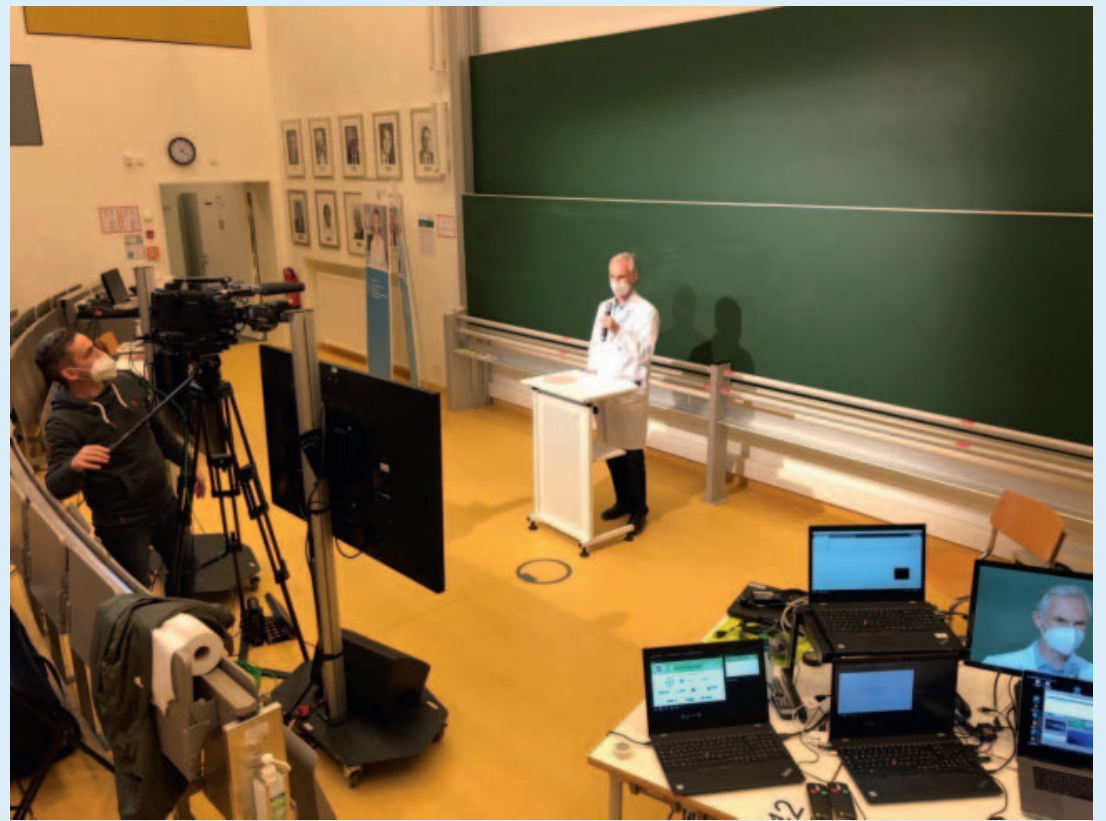

Gastgeber Professor Meinrad Beer. () Meinrad Beer

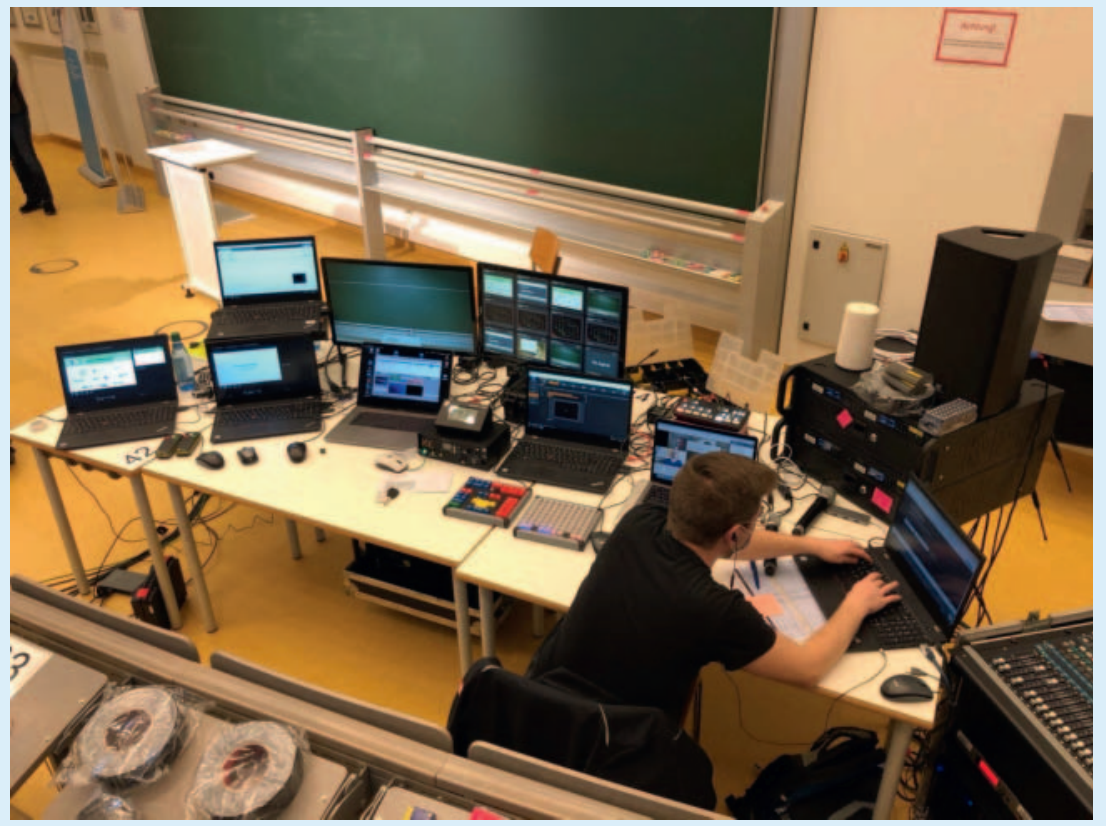

(c) Meinrad Beer 


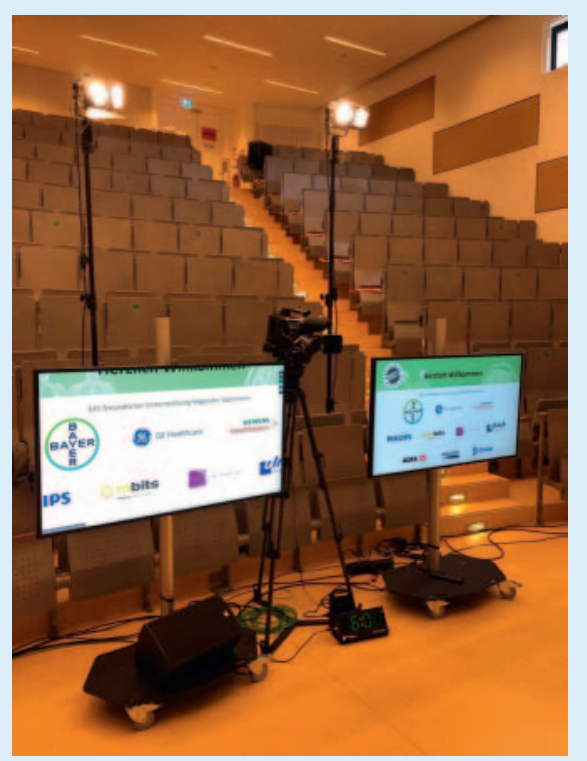

Trotz des großen Erfolges unter den aktuellen Rahmenbedingungen bin ich mir sicher, dass ein Wiedersehen beim Radiologie Update in Ulm in Präsenz vom 25.-26. März 2022 ein besonderer Moment sein wird, dann auch mit der gewohnten abrundenden Abendveranstaltung. Ergänzend werden wir eine Onlineteilnahme im Hybridformat anbieten.

Auf Ihr Kommen nach Ulm wie Ihre Teilnahme per Web freue ich mich!

Prof. Dr. Meinrad Beer Ulm

(c) Meinrad Beer 